\title{
Variant Histology: The Impact on Oncological Outcomes of Patients with Urothelial Carcinoma of The Bladder Treated with Radical Cystectomy
}

\author{
(1) Berk Hazır, (1) Hakan Bahadır Haberal, (1) Kadir Emre Baltacı, (1) Parviz Shahsuvarli, (1) Bülent Akdoğan, (1) Cenk Yücel Bilen, \\ (D) Mustafa Sertaç Yazıcı \\ Hacettepe University Faculty of Medicine, Department of Urology, Ankara, Turkiye
}

\section{What's known on the subject? and What does the study add?}

The association of variant histologies of bladder cancer with prognosis is a current debate in the literature. Our study illustrates that variant histologies of bladder cancer are related to poor survival rate. However, lymph node metastasis have been identified as the most significant factor for overall and cancer-specific survival.

\begin{abstract}
Objective: To investigate the impact of variant histology (VH) of urothelial carcinoma (UC) of the bladder on oncologic outcomes after radical cystectomy (RC).

Materials and Methods: We identified 125 patients with cT2-T4NOM0 UC who underwent RC without perioperative systemic therapy between 2014 and 2019 at a single tertiary care referral center. The Mann-Whitney U test and chi-square test were used to compare the statistically significant differences in medians and proportions, respectively. The Kaplan-Meier method and Cox regression analyses tested the effect of different VH on cancer-specific survival (CSS) and overall survival (OS).

Results: Of 125 patients, 70 (56\%) had pure UC, whereas $55(44 \%)$ had VH. The mean patient age and the median follow-up were $63.6 \pm 9.7$ years and 12.5 (3-72) months. The female to male ratio was $13 / 112$. The presence of lymphovascular invasion, locally advanced stage ( $\geq \mathrm{pT3}$ ), and recurrence status were significantly higher in patients with VH than those with pure UC. In all patients, the presence of VH was not significantly associated with the presence of lymph node (LN) metastasis. In the multivariable Cox regression analyses, the type of UC [hazard ratio (HR) 1.80, 95\% confidence interval $(\mathrm{Cl}) 1.00-3.24, \mathrm{p}=0.050$ ] and age $(\mathrm{HR}=1.050,95 \% \mathrm{Cl} 1.016-1.086, \mathrm{p}=0.004)$ was associated with the OS, whereas the $\mathrm{LN}$ metastases was associated the CSS $(\mathrm{HR}=2.962,95 \% \mathrm{Cl} 1.456-6.027, \mathrm{p}=0.003)$ and $\mathrm{OS}(\mathrm{HR}=3.211,95 \% \mathrm{Cl} 1.778-5.799, \mathrm{p}<0.001)$.

Conclusion: Our study demonstrated that VH in bladder cancer was associated with unfavorable clinicopathological features and a poorer OS prognosis. However, VH is not independently significant with the CSS. In addition, this study confirms that the LN metastasis represents a robust and independent predictor of inferior CSS and OS.
\end{abstract}

Keywords: Variant histology, survival, urothelial carcinoma

\section{Introduction}

Bladder cancer $(\mathrm{BC})$ is a common malignancy. It rates seventh in males, whereas eleventh when both genders are considered (1). The most common histology of BC is urothelial carcinoma (UC) (2). Except for pure UC, several different variant histologies (VH) are present, which include urothelial and non-urothelial, and were found in up to 33\% of radical cystectomy (RC) specimens (3).

$\mathrm{VH}$ is associated with determined predictors of aggressive behavior (4). Several studies have identified a relationship with the adverse outcome; however, this adverse outcome does not remain significant on the multivariable analysis $(4,5)$. These variants gained attention for their aggressiveness; however,

Correspondence: Berk Hazır MD, Hacettepe University Faculty of Medicine, Department of Urology, Ankara, Turkiye

Phone: +90 5554129800 E-mail: berkhazir@gmail.com ORCID-ID: orcid.org/0000-0002-8907-8781

Received: 23.01 .2021

Accepted: 23.03.2021

Cite this article as: Hazır B, Haberal HB, Baltacı KE, Shahsuvarli P, Akdoğan B, Bilen CY, Yazıcı MS. Variant Histology: The Impact on Oncological Outcomes of Patients with Urothelial Carcinoma of The Bladder Treated with Radical Cystectomy. J Urol Surg 2021;8(4):243-247.

๑Copyright 2021 by the Association of Urological Surgery / Journal of Urological Surgery published by Galenos Publishing House. 
the studies investigating the impact of $\mathrm{VH}$ on the oncologic outcomes have obscure results $(3,5,6)$.

This research was single-institutional and involved pure UC and VH containing pure variant type and mixed-type UC with a variant pattern. Furthermore, this study aimed to assess the clinicopathological features and prognosis in patients with pure $\mathrm{UC}$ and $\mathrm{VH}$ who underwent RC and lymph node (LN) dissection (LND).

\section{Materials and Methods}

This study included 192 patients who underwent RC and bilateral pelvic LND from January 2014 to December 2019 due to $B C$ after the institutional review board approval (no: GO 21/30). All surgeries were performed at a single tertiary referral center. Patients' preoperative evaluation comprised chest and pelvic/abdominal imaging. While patients underwent $\mathrm{X}$-ray or computed tomography for chest imaging, computed tomography scan and magnetic resonance imaging was used for pelvic/abdominal imaging. Pelvic LND was performed routinely with $\mathrm{RC}$, and different surgeons used standard techniques over the study's timeframe. Patients with clinically metastatic disease ( $\mathrm{CN} 1$ or $\mathrm{cM} 1)$ were excluded when these data were being created. Patients with non-urothelial histology (e.g., pure squamous cell carcinoma and adenocarcinoma) $(n=45)$ were excluded. Furthermore, patients who received systemic neoadjuvant chemotherapy were excluded $(n=22)$.

Expert genitourinary pathologists examined every surgical specimen. Our analyses on VH classification included micropapillary, sarcomatoid, lymphoepithelial, small cell, squamous, plasmacytoid, trophoblastic, nested, and glandular. The uropathological assessment of more than one $\mathrm{VH}$ was classified as mixed variants. Due to patient scarcity, all variant types were grouped under one group and compared with pure UC. LN status and tumor stage were divided into two groups [(NO-Nx and N1-N2), ( $\leq \mathrm{pT} 2$ and $\geq \mathrm{pT} 3)$, respectively].

The two groups were compared in terms of gender, age, comorbid disease, smoking history, surgical margin, adjuvant chemotherapy, LN involvement, accompanying CIS, lymphovascular invasion (LVI), tumor stage, recurrence, cancerspecific survival (CSS), and overall survival (OS). Univariate and multivariate statistical analyses were conducted to define the factors affecting CSS and OS.

The follow-up data of all patients were complete. Clinic and radiological follow-up were started about three months after surgery. Computed tomography was conducted in examinations of all patients as radiological imaging. Physical examination accompanied laboratory analysis, abdominal ultrasonography, neobladder cystoscopy, urine cytology, and urethral washings. A bone scan was performed with any present indication.

\section{Statistical Analyses}

Frequencies and proportions were the focal points of descriptive statistics of categorical variables. Mean \pm standard deviation was used for parametric variables, while the median and interquartile range were used for non-parametric variables. The t-test and chi-square test were used to compare the statistical significance of variances in means and proportions, respectively. The effect of different histopathological variants on CSS and OS was tested by the Kaplan-Meier method and Cox regression analyses. Statistical significance was taken at $p<0.05$. The Statistical Package for the Social Sciences v.22.0 was used to conduct statistical analyses (IBM Corp., Armonk, NY).

\section{Results}

The mean patient age and the median follow-up period were $63.6 \pm 9.7$ years and $12.5(3-72)$ months. The female to male ratio was $13 / 112$. The pure UC and VH percentages and frequencies were shown in Table 1, and patient demographics and pathological characteristics are illustrated in Table 2. Patients with VH had a higher locally advanced stage disease ( $\geq \mathrm{pT} 3)$ $(p<0.001)$, LVI $(p<0.001)$, and recurrence $(p=0.008)$ than those with pure UC. Nevertheless, the similarity was found between patients with $\mathrm{VH}$ and those with UC regarding age, gender, surgical margin, adjuvant chemotherapy, accompanying CIS, comorbid disease, smoking history, and LN involvement.

Concerning prognostic values, patients with VH had worse CSS and OS than those with pure UC in the Kaplan- Meier analyses ( $p=0.013$ and $p=0.035$, respectively; see Figure 1$)$.

The 2-year CSS and OS were $65.5 \%$ and $56.3 \%$, respectively. The type of UC, LVI, T stage, LN metastasis, and positive surgical

Table 1. Frequencies and percentages of pathological variants

\begin{tabular}{|l|l|l|}
\hline & N & \% \\
\hline Pure urothelial & 70 & 56 \\
\hline Variant histology & 55 & 44 \\
\hline Micropapillary & 14 & 11.2 \\
\hline Sarcomatoid & 9 & 7.2 \\
\hline Lymphoepithelial & 2 & 1.6 \\
\hline Small cell & 1 & 0.8 \\
\hline Squamous & 13 & 10.4 \\
\hline Plasmositoid & 3 & 2.4 \\
\hline Trophoblastic & 1 & 0.8 \\
\hline Nested & 5 & 4 \\
\hline Glandular & 3 & 2.4 \\
\hline Mixt & 4 & 3.2 \\
\hline
\end{tabular}


Table 2. Patient demographics and clinical features of pathologic variants

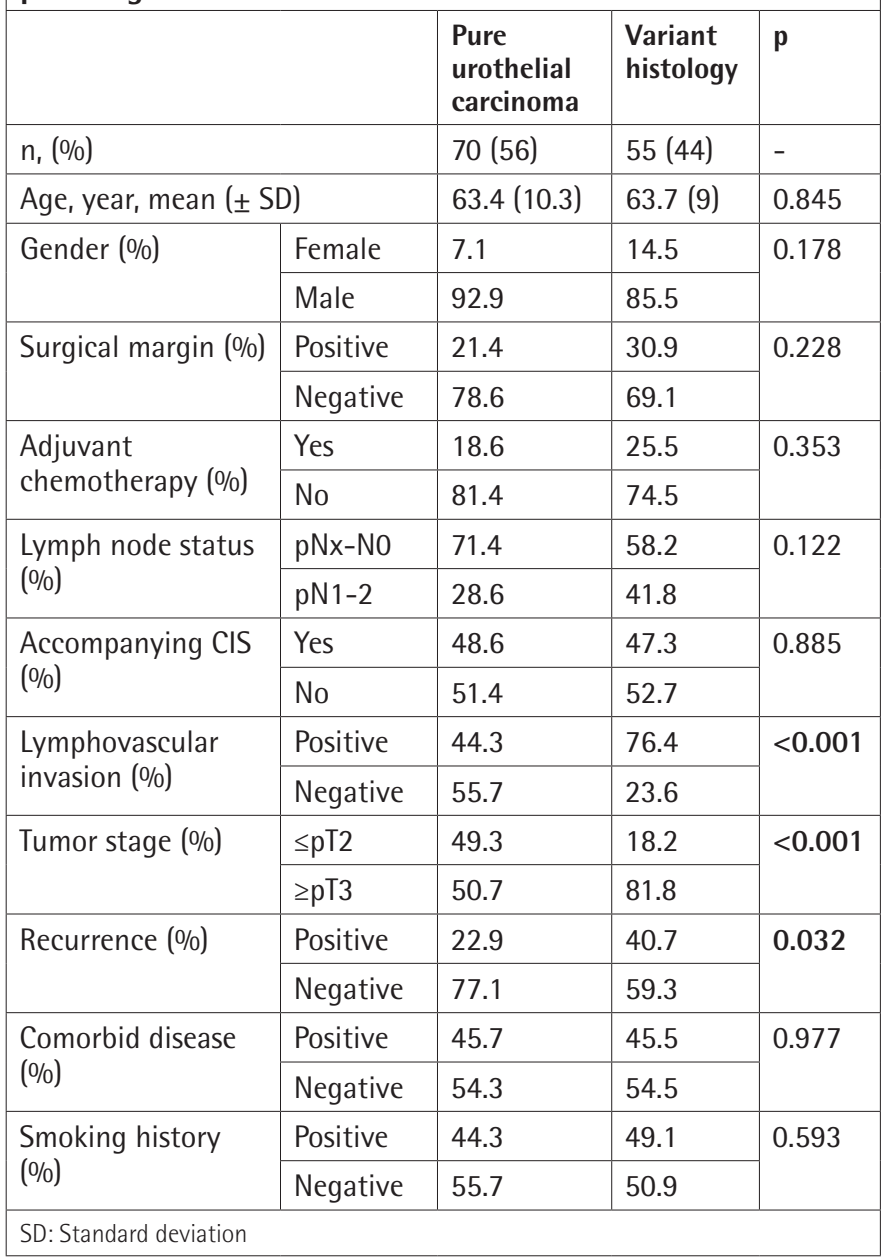
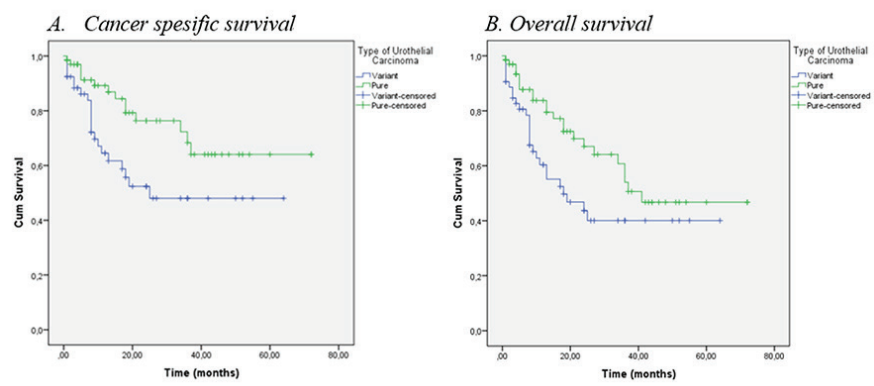

Figure 1. Survival analyses using Kaplan-Meier methods for pure urothelial carcinoma and histologic variants

margin (PSM) were associated with the CSS in the univariate analysis $(p=0.013, p=0.004, p=0.006, \quad p<0.001, p=0.011$, respectively). The type of UC, LVI, T stage, LN metastasis, PSM, and age were associated with $0 \mathrm{~S}$ in the univariate analysis $(p=0.035, p=0.004, p=0.005, p<0.001, p=0.018$, and $p=0.009$ ， respectively) (Table 3 ).

Only LN metastasis was identified as a significant prognostic factor for the CSS in the multivariate analysis ( $p=0.003$ ). The type of UC, LN metastasis, and age were identified as significant prognostic factors for the $\mathrm{OS}$ in the multivariate analysis ( $p=0.05, p<0.001, p=0.004$, respectively) (Table 4$)$.

\begin{tabular}{|c|c|c|c|c|c|}
\hline \multirow{2}{*}{\multicolumn{2}{|c|}{ Parameters }} & \multicolumn{4}{|c|}{ Univariate analysis } \\
\hline & & $\begin{array}{l}\text { 2-year } \\
\text { CSS } \\
(\%)\end{array}$ & $\mathbf{p}$ & $\begin{array}{l}\text { 2-year } \\
\text { OS } \\
(\%)\end{array}$ & $\mathbf{p}$ \\
\hline \multirow[t]{2}{*}{ Gender } & Female & 55.4 & \multirow[t]{2}{*}{0.395} & 48.5 & \multirow[t]{2}{*}{0.529} \\
\hline & Male & 66.4 & & 57.1 & \\
\hline \multirow{2}{*}{$\begin{array}{l}\text { Type of urothelial } \\
\text { carcinoma }\end{array}$} & Pure & 76.4 & \multirow[t]{2}{*}{0.013} & 67 & \multirow[t]{2}{*}{0.035} \\
\hline & Variant & 52.4 & & 43.7 & \\
\hline \multirow{2}{*}{$\begin{array}{l}\text { Lymphovascular } \\
\text { invasion }\end{array}$} & Yes & 55.4 & \multirow[t]{2}{*}{0.004} & 45.1 & \multirow[t]{2}{*}{0.004} \\
\hline & No & 79.7 & & 71.8 & \\
\hline \multirow[t]{2}{*}{ T-stage } & $\leq \mathrm{pT} 2$ & 82.9 & \multirow[t]{2}{*}{0.006} & 78.2 & \multirow[t]{2}{*}{0.005} \\
\hline & $\geq \mathrm{pT} 3$ & 55.6 & & 44 & \\
\hline \multirow{2}{*}{$\begin{array}{l}\text { Lymph node } \\
\text { metastasis }\end{array}$} & $\mathrm{Nx}-\mathrm{NO}$ & 81.2 & \multirow[t]{2}{*}{$<0.001$} & 74.5 & \multirow[t]{2}{*}{$<0.001$} \\
\hline & $\mathrm{N} 1-\mathrm{N} 2$ & 40.6 & & 28.1 & \\
\hline \multirow{2}{*}{$\begin{array}{l}\text { Adjuvant } \\
\text { chemotherapy }\end{array}$} & Yes & 57.8 & \multirow[t]{2}{*}{0.717} & 49.2 & 0.852 \\
\hline & No & 68.2 & & 58.9 & \\
\hline \multirow[t]{2}{*}{ Surgical margin } & Negative & 72.3 & \multirow[t]{2}{*}{0.011} & 63 & \multirow[t]{2}{*}{0.018} \\
\hline & Positive & 49.6 & & 41.2 & \\
\hline \multirow{2}{*}{$\begin{array}{l}\text { Accompanying } \\
\text { CIS (\%) }\end{array}$} & Yes & 63.5 & \multirow[t]{2}{*}{0.848} & 52 & \multirow[t]{2}{*}{0.810} \\
\hline & No & 68.8 & & 61.7 & \\
\hline \multirow[t]{2}{*}{ Age $( \pm$ SD) } & CSS & $\begin{array}{l}63.1 \\
(10)\end{array}$ & \multirow[t]{2}{*}{0.440} & $\begin{array}{l}66.4 \\
(9)\end{array}$ & \multirow[t]{2}{*}{0.009} \\
\hline & CSD & $\begin{array}{l}64.6 \\
(9.2)\end{array}$ & & $\begin{array}{l}61.7 \\
(9.9)\end{array}$ & \\
\hline
\end{tabular}

CSD: Cancer-specific death, CSS: Cancer-specific survival, SD: Standard deviation, OS: Overall survival

\section{Discussion}

Given the development of literature about the importance of variant tumors as one of the crucial factors of therapeutic approach, our referral center has a current series that includes nonmetastatic $\mathrm{BC}$ that are treated with $\mathrm{RC}$ and focuses on the incidence and histological variant effect on survival in patients. Our study revealed that VH was remarkably high at the time of RC, contrary to previous studies (7-9). This may be related to the fact that our data is more recent than previous studies and the increased knowledge and awareness of genitourinary pathologists in $\mathrm{VH}(3,10)$. In our study, most patients who had VH were diagnosed with micropapillary and squamous differentiation. Our results are consistent with prior findings on this issue (11-13). Monn et al. (11) investigated a patient cohort that includes patients who underwent RC from 2008 to 2013. VH incidence was $26 \%$. In addition, squamous and 
Table 4. Multivariate analysis for cancer-specific survival (CSS) and overall survival (OS)

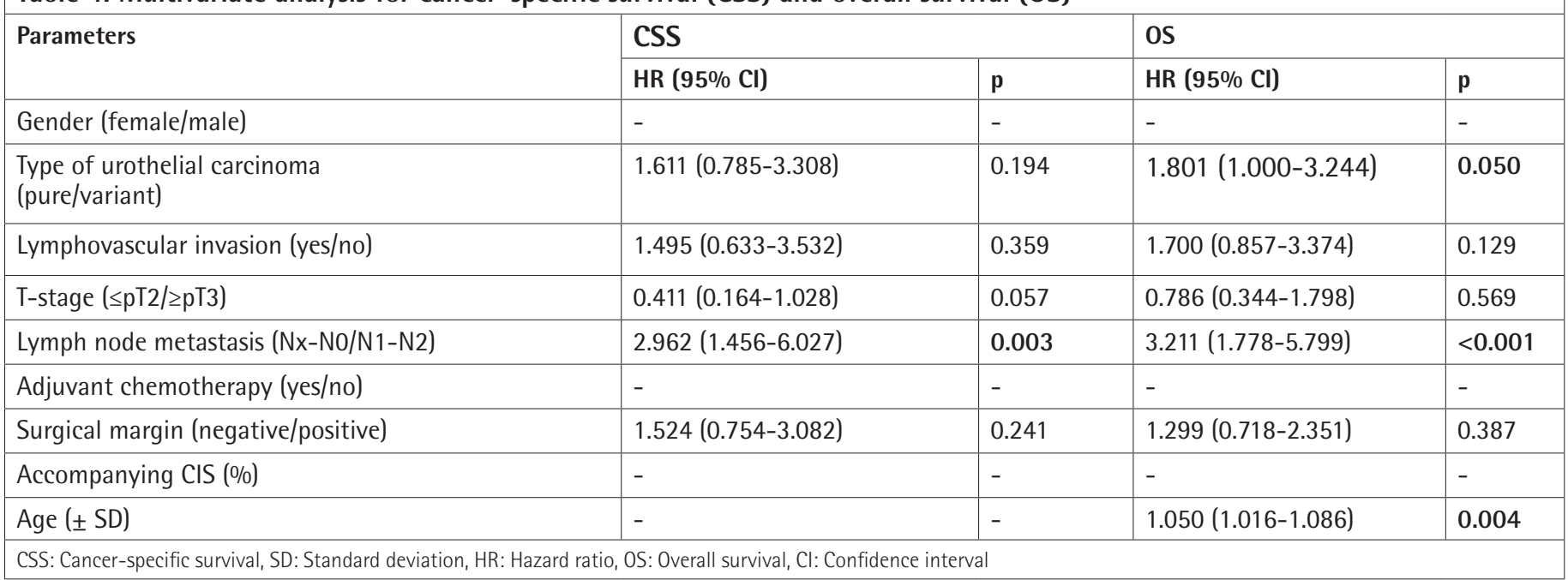

micropapillary variants were the most common variants. Other data is presented in the literature, including 1,984 patients who underwent RC with bilateral LND from 2000 to 2008 at five referral centers (13). The VH incidence was reported to be $24.6 \%$, with squamous variants being the most frequent.

VH was confirmed to harbor biologically aggressive disease characteristics, such as the presence of LVI, advanced tumor stage, and recurrence development $(7,8)$. Regrettably, our data size is not adequately large to provide sufficient statistical power. Thus, individual variant subgroups could not be analyzed in the variant population. The presence of VH was associated with both CSS and OS in the univariable Kaplan- Meier analysis. However, the association was not found with CSS in a multivariable analysis adjusted for standard clinicopathological predictors such as LN parameters, advanced T stage, and surgical margin. Overall, the influence of $\mathrm{VH}$ on survival is still a disputable issue. Few previous studies found an association of $\mathrm{VH}$ with unfavorable pathological characteristics including LN status $(8,9,14)$; however, these results were not associated with low survival metrics in adjusted outcome analyses of contemporary series $(13,14)$. In our study, only LN involvement influenced the prognosis of both the CSS and OS independently. Regardless of variant differentiation, $\mathrm{LN}$ metastasis is the imperative risk factor for the systemic spread and subsequently fatal disease course. Therefore, early diagnose of LN metastasis by genetic and molecular characterization might be a popular topic in the future. Thus, possible multimodal treatments will be individually modified in UC, as previously demonstrated in oral squamous carcinoma (15).

Contrarily, the quality of $L N$ dissection might explain this paradoxical observation between adverse pathology in $\mathrm{VH}$ but no association with LN positivity, which appeared as the most critical factor for survival in this study. The surgeon's experience and the patient's anatomy might be significant factors for quality. Unfortunately, the quality was not similar between the patient groups.

Our study found no significant difference in the oncological outcomes in terms of adjuvant chemotherapy. This result corresponds with previous literature $(9,11,16)$. However, Bellmunt et al. (17) conducted a randomized phase III trial. They compared observation with four paclitaxel, gemcitabine, and cisplatin (PGC) courses in the clinical setting. This study strongly recommends that PGC adjuvant therapy ameliorates the CSS and $\mathrm{OS}$ in high-risk invasive BC. Thus, we could not certainly answer whether adjuvant chemotherapy would have an advantage for prognosis or not. This treatment can be considered with the clinician's preference.

\section{Study Limitations}

Our study has several limitations. First, this study was retrospectively conducted and provided a limited sample size due to its single-center nature. Second, the VH percentage was not evaluated since it was not reported in pathological specimens. Additionally, we did not determine a cut-off value for the amount of dedifferentiated tissue that is required for a specimen to be categorized as mixed histological type. However, evidence does not exist about the possible survival forecast of this parameter (18). Third, the follow-up time was short, and we were unable to evaluate the effect that significant findings may have had on oncologic or survival outcomes with long follow-up times. Fourth, due to the rarity of $\mathrm{VH}$ subgroups, they were incorporated into the same group during analysis. Fifth, due to retrospective analysis, the status of the smokers was not determined. Some studies found that current smokers had a higher risk of recurrence or progression than former smokers (19). Finally, the patients who received neoadjuvant chemotherapy were excluded due to the low number of patients, and the decision of neoadjuvant chemotherapy was 
surgeon and patient-dependent in our clinic. Thus, this situation can cause a risk of bias.

\section{Conclusion}

This current research confirmed that $\mathrm{VH}$ incidence is frequent at RC specimens; moreover, the presence of VH correlated with a high risk of recurrence and worse clinical outcomes for OS. However, VH did not significantly change the incidence of the LN metastases. Our study confirmed that the LN metastasis represents a robust and independent predictor of lower CSS and OS.

\section{Ethics}

Ethics Committee Approval: This study included 192 patients who underwent RC and bilateral pelvic LND from January 2014 to December 2019 due to BC after the institutional review board approval (no: G0 21/30).

Informed Consent: Retrospective study.

Peer-review: Externally and internally peer-reviewed.

\section{Authorship Contributions}

Surgical and Medical Practices: B.A., C.Y.B., M.S.Y., Concept: B.A., C.Y.B., M.S.Y., Design: B.H., Data Collection or Processing: B.H., K.E.B., P.S., Analysis or Interpretation: H.B.H., Literature Search: B.H., Writing: B.H., H.B.H., M.S.Y.

Conflict of Interest: No conflict of interest was declared by the authors.

Financial Disclosure: The authors declare that they have no relevant financial.

\section{References}

1. Ferlay J, Steliarova-Foucher E, Lortet-Tieulent J, Rosso S, Coebergh JW, Comber H, Forman D, Bray F. Cancer incidence and mortality patterns in Europe: estimates for 40 countries in 2012. Eur J Cancer 2013;49:13741403.

2. Rogers CG, Palapattu GS, Shariat SF, Karakiewicz PI, Bastian PJ, Lotan $Y$, Gupta A, Vazina A, Gilad A, Sagalowsky Al, Lerner SP, Schoenberg MP. Clinical outcomes following radical cystectomy for primary nontransitional cell carcinoma of the bladder compared to transitional cell carcinoma of the bladder. J Urol 2006;175:2048-2053.

3. Humphrey PA, Moch H, Cubilla AL, Ulbright TM, Reuter VE. The 2016 WHO Classification of Tumours of the Urinary System and Male Genital OrgansPart B: Prostate and Bladder Tumours. Eur Urol 2016;70:106-119.

4. Moschini M, D'Andrea D, Korn S, Irmak Y, Soria F, Compérat E, Shariat SF. Characteristics and clinical significance of histological variants of bladder cancer. Nat Rev Urol 2017;14:651-668.

5. Li Q, Assel M, Benfante NE, Pietzak EJ, Herr HW, Donat M, Cha EK, Donahue TF, Bochner BH, Dalbagni G. The Impact of Plasmacytoid Variant Histology on the Survival of Patients with Urothelial Carcinoma of Bladder after Radical Cystectomy. Eur Urol Focus 2019;5:104-108.
6. Wang JK, Boorjian SA, Cheville JC, Kim SP, Tarrell RF, Thapa P, Frank I. Outcomes following radical cystectomy for micropapillary bladder cancer versus pure urothelial carcinoma: a matched cohort analysis. World J Urol 2012;30:801-806.

7. Lin-Brande M, Pearce SM, Ashrafi AN, Nazemi A, Burg ML, Ghodoussipour S, Miranda G, Djaladat H, Schuckman A, Daneshmand S. Assessing the Impact of Time to Cystectomy for Variant Histology of Urothelial Bladder Cancer. Urology 2019;133:157-163.

8. Koguchi $D$, Matsumoto $K$, Ikeda $M$, Taoka $Y$, Hirayama $T$, Murakami $Y$, Utsunomiya T, Matsuda D, Okuno N, Irie A, Iwamura M. Histologic variants associated with biological aggressiveness and poor prognosis in patients treated with radical cystectomy. Jpn J Clin Oncol 2019;49:373-378.

9. Moschini M, Dell'Oglio P, Luciano' R, Gandaglia G, Soria F, Mattei A, Klatte T, Damiano R, Shariat SF, Salonia A, Montorsi F, Briganti A, Colombo R, Gallina A. Incidence and effect of variant histology on oncological outcomes in patients with bladder cancer treated with radical cystectomy. Urol Oncol 2017;35:335-341.

10. Shah RB, Montgomery JS, Montie JE, Kunju LP. Variant (divergent) histologic differentiation in urothelial carcinoma is under-recognized in community practice: impact of mandatory central pathology review at a large referral hospital. Urol Oncol 2013;31:1650-1655.

11. Monn MF, Kaimakliotis HZ, Pedrosa JA, Cary KC, Bihrle R, Cheng L, Koch MO. Contemporary bladder cancer: variant histology may be a significant driver of disease. Urol Oncol 2015;33:18.e15-18.e20.

12. Willis DL, Porten SP, Kamat AM. Should histologic variants alter definitive treatment of bladder cancer? Curr Opin Urol 2013;23:435-443.

13. Xylinas $E$, Rink $M$, Robinson $B D$, Lotan $Y$, Babjuk $M$, Brisuda $A$, Green DA, Kluth LA, Pycha A, Fradet Y, Faison T, Lee RK, Karakiewicz Pl, Zerbib M, Scherr DS, Shariat SF. Impact of histological variants on oncological outcomes of patients with urothelial carcinoma of the bladder treated with radical cystectomy. Eur J Cancer 2013;49:1889-1897.

14. Marks $P$, Gild $P$, Soave $A$, Janisch $F$, Minner S, Engel O, Vetterlein MW, Shariat SF, Sauter G, Dahlem R, Fisch M, Rink M. The impact of variant histological differentiation on extranodal extension and survival in node positive bladder cancer treated with radical cystectomy. Surg Oncol 2019;28:208213.

15. Wang W, Lim WK, Leong HS, Chong F, Lim TK, Tan DS, Teh BT, Iyer NG. An eleven gene molecular signature for extra-capsular spread in oral squamous cell carcinoma serves as a prognosticator of outcome in patients without nodal metastases. Oral Oncol 2015;51:355-362.

16. Cognetti F, Ruggeri EM, Felici A, Gallucci M, Muto G, Pollera CF, Massidda B, Rubagotti A, Giannarelli D, Boccardo F; Study Group(t). Adjuvant chemotherapy with cisplatin and gemcitabine versus chemotherapy at relapse in patients with muscle-invasive bladder cancer submitted to radical cystectomy: an Italian, multicenter, randomized phase III trial. Ann Oncol 2012;23:695-700.

17. Bellmunt J, von der Maase H, Mead GM, Skoneczna I, De Santis M, Daugaard G, Boehle A, Chevreau C, Paz-Ares L, Laufman LR, Winquist E, Raghavan D, Marreaud S, Collette S, Sylvester R, de Wit R. Randomized phase III study comparing paclitaxel/cisplatin/gemcitabine and gemcitabine/cisplatin in patients with locally advanced or metastatic urothelial cancer without prior systemic therapy: EORTC Intergroup Study 30987. J Clin Oncol 2012;30:1107-1113.

18. Kim SP, Frank I, Cheville JC, Thompson RH, Weight CJ, Thapa P, Boorjian SA. The impact of squamous and glandular differentiation on survival after radical cystectomy for urothelial carcinoma. J Urol 2012;188:405-409.

19. Crivelli JJ, Xylinas E, Kluth LA, Rieken M, Rink M, Shariat SF. Effect of smoking on outcomes of urothelial carcinoma: a systematic review of the literature. Eur Urol 2014;65:742-754. 